\title{
Child dietary diversity and food (in)security as a potential correlate of child anthropometric indices in the context of urban food system in the cases of north- central Ethiopia
}

\author{
Amare Molla Dinku', Tefera Chane Mekonnen ${ }^{2 *}$ and Getachew Shumye Adilu ${ }^{3}$
}

\begin{abstract}
Objective: To investigate the relation of child dietary diversity and household food insecurity along with other socio-demographic with child anthropometric indices in north-central Ethiopia, an area with a high level of food insecurity and inadequate diet quality.

Design: A community-based cross-sectional study was used.

Settings: The study was conducted in Dessie and Combolcha towns of north-central Ethiopia from April to May 2018.

Participants: Randomly selected 512 mother-child pairs with child's age range of 6-59 months.

Results: The mean $( \pm$ SD) scores of weight-for-height/length, height/length-for-age, weight-for-age, and BMI-forage Z-scores were $1.35( \pm 2.03),-1.89( \pm 1.79), 0.05( \pm 1.54)$, and $1.39( \pm 2.06)$, respectively. From all anthropometric indicators, stunting and overweight/obesity remained the severe public issues hitting $43 \%$ and $42 \%$ of the children, respectively. In the model, mothers' age and education and child's age, sex, and dietary diversity were significantly related with child height-for-age Z-score while place of residence, sex of household head, child's age, and dietary diversity score were the predictors of child BMI-for-age Z-score in the urban contexts of the study area. Nevertheless, food insecurity was not related to any of the child anthropometric indices.

Conclusion: The double burden of malnutrition epidemics (stunting and obesity) coexisted as severe public health concerns in urban settings. Anthropometric statuses of children were affected by multidimensional factors and seek strong integration and immediate intervention of multiple sectors.
\end{abstract}

Keywords: Food insecurity, Dietary diversity, Urban food system, Child anthropometry, North-central Ethiopia

\footnotetext{
* Correspondence: teferachane@gmail.com

${ }^{2}$ Researcher at the School of Public Health, College of Medicine and Health Sciences, Wollo University, Dessie, Ethiopia

Full list of author information is available at the end of the article
}

C C The Author(s). 2020 Open Access This article is licensed under a Creative Commons Attribution 4.0 International License, which permits use, sharing, adaptation, distribution and reproduction in any medium or format, as long as you give appropriate credit to the original author(s) and the source, provide a link to the Creative Commons licence, and indicate if changes were made. The images or other third party material in this article are included in the article's Creative Commons licence, unless indicated otherwise in a credit line to the material. If material is not included in the article's Creative Commons licence and your intended use is not permitted by statutory regulation or exceeds the permitted use, you will need to obtain permission directly from the copyright holder. To view a copy of this licence, visit http://creativecommons.org/licenses/by/4.0/ The Creative Commons Public Domain Dedication waiver (http://creativecommons.org/publicdomain/zero/1.0/) applies to the data made available in this article, unless otherwise stated in a credit line to the data. 


\section{Introduction}

Currently, Africa is experiencing rapid demographic changes which are partly driven by the increasing migration of individuals to urban areas and rapid socioeconomic transitions [1-3]. Nearly, one third of the population of Africa live in cities, and this figure is expected to be more than one half by the end of 2033 [4]. In East African countries, the average rate of urban population growth projection from 1995 to 2025 was $4.7 \%$, and after $2025,41.2 \%$ of the regional population will be expected to live in urban areas $[5,6]$. Similarly, in Ethiopia, nearly 20 million people are currently living in urban areas where the annual urban population growth rate is $4.8 \%$, which is equivalent to the East African average [7]. Such urbanization changes the food habits and lifestyles of the urban population, which placed an additional burden on the nutritional problems of children [8-10]. Due to the changes in people's food environments and dietary habits, nutrition transition has been occurring in the last decade [9]. This in turn results in a modification in food patterns which are associated with the increasing levels of obesity and nutrition-related non-communicable diseases coexisting with malnutrition $[1,2,11]$.

In the early years, diet-related poor child health outcomes in urban areas are increasing and have negative ripple effects on the timing of entry into school educational attainment which ultimately resulting in intergenerational poverty and malnutrition [4]. Thus, this malnutrition prevents children from reaching their full physical and mental potential [12].

Even though the prevalence of stunting and acute malnutrition (wasting or low weight-for-height) in Ethiopia has decreased over the past decade, it remains high, with $38 \%$ of children under 5 years stunted and $10 \%$ wasted [13]. Stunting is even higher in Amhara regional state with $46 \%$ and more persistent in north-central Ethiopia [13, 14]. Recognizing this, the Government of Ethiopia had launched a nutrition program called "Seqota Declaration" to be executed from 2016 to 2030 focused on ending child undernutrition by 2030 [14]. Therefore, the aim of this study was to explore the nutritional status of 6-59-month children who live in urban areas in north-central Ethiopia and to investigate their potential covariates.

\section{Methods and materials}

\section{Study design, settings, and participants}

We employed a cross-sectional study in Dessie and Combolcha towns from April to May 2018. Dessie and Combolcha cities are found in South Wollo Zone, north-central Ethiopia, with elevations between 1842 and $2550 \mathrm{~m}$ above sea level, as Combolcha takes the lower elevation. There is more than $58 \%$ of the total rainfall in the summer season, while $18 \%$ falls in spring and less than $5 \%$ of the total occurring during winter. The uneven distribution of rainfall gives rise to a serious shortage of water during the dry season in the area [15]. Most of the time, small business/self-employment and government salary/wages were still the main livelihood activities for most urban households. Considering variations by town with regard to food security conditions, Dessie had the second-highest poor consumption percentage of households (47\%) [16].

All children aged between 6 and 59 months that have resided in the study area for the last 6 months were included in the study sample, while any child with a severe medical problem, lack of household head or caregivers, or physical deformity was excluded from the study. The largest sample (512 mother-child pairs) was taken from a study conducted in Ethiopia by considering maternal education as a predictor for child stunting and overweight [17] with the assumptions that $95 \%$ of confidence level, $80 \%$ of power, 1.7 the odds of being stunting when the mother is not educated, and $24.3 \%$ of child stunting among uneducated mothers. Three sub-cities from Dessie and two kebeles from Combolcha town were selected randomly. We conducted a preliminary census in the selected catchments to identify target participants. The samples allocated to the total populations with the eligible study subjects proportionally, and the younger child was selected if more than one child were found in the household.

\section{Data collection and measurements}

A predesigned and pre-tested questionnaire was used to interview the study participants to elicit information on family and child socio-demographic characteristics like residence, religion, type of family, education, occupation of parents, socio-economic condition (household expenditure and wealth index), household food insecurity, child feeding characteristics, and anthropometric measurements.

The questionnaire was standardized to assure the quality and validity of the data and translated into the local language (Amharic) and was re-translated to English. All assessment team members were able to administer the questionnaires properly; a total of 5 days of rigorous training of enumerators and supervisors was given by the three authors. Before the actual data collection work, data collectors and supervisors carried out role-play practices and they filled the pre-test activities in the community other than target areas. Data collectors were responsible for filling out the data using mobile devices while supervisors checked the completeness and correctness of the filled data before sending it to the researchers. At the end of every data collection day, each questionnaire was examined for completeness and consistency by the supervisors and finally cross-checked 
by the researchers. A regular adjustment has been made for anthropometric measurements in each circumstance.

The household socio-economic status (SES) was parameterized by the principal component analysis (PCA) method using house properties confirmed by the questionnaire: property owned, source of drinking water, type of toilet facility, and type of flooring, wall material, and roof material. The score in the first PCA component was used as an asset index of SES status for each household [18], and households were categorized into tertiles as poor, medium, and rich. The household food security status was assessed using the Household Food Insecurity Access Scale (HFIAS), and households were classified as food secure if it had not experienced any food insecurity conditions or had rarely worried about not having enough food, whereas food-insecure households were categorized as mild, moderate, and severe in accordance with the guidelines [19]. For data validation, Cronbach's alpha coefficient, which is a measure of the internal consistency of a scale, was used to confirm the reliability of the HFIAS and the household SES measure. An alpha value of more than 0.7 indicated that the measure was acceptable.

Child dietary assessment was done based on the procedure recommended by the Food and Agriculture Organization (FAO) [20]. Mothers or caregivers were asked whether the child consumed more than a spoonful of the seven food groups (namely, cereals, tubers and roots, legumes and nuts, vitamin A-rich fruits and vegetables, flesh foods, milk and milk products, eggs, and other fruits and vegetables) within the past $24 \mathrm{~h}$ recall. The child food groups were developed based on the food items recommended in the Infant and Young Child Feeding (IYCF) guidelines. The total dietary diversity score was generated with the response of "yes" and "no" for each child. In accordance with the IYCF guidelines, a child's DDS was categorized as poor and good [21].

\section{Child anthropometry}

Child weight and length/height were taken by following critical and meticulous procedures. Ages were also recorded from immunization cards, direct probing of mothers, or birth certificates. The weight of children was taken using an electronic digital weight scale and recorded in kilograms to the nearest $0.1 \mathrm{~kg}$ [22] and with light clothes and no shoes. Two measurements were recorded for each child, and the average result was taken. In every instance of measurement, the scale was checked for its reading and calibration. It was also standardized with $2 \mathrm{~kg}$ iron rod before taking the measure. The length/height of the child was also documented twice. The length was measured for children less than 24 months (child unable to stand erectly or $<85 \mathrm{~cm}$ ) in recumbent position using wood-made sliding length board with the help of two examiners. For children greater than 24 months, height was measured using a sliding height board in Frank fret position and recorded in centimeters to the nearest $0.1 \mathrm{~cm} \mathrm{[22].} \mathrm{During} \mathrm{this} \mathrm{proced-}$ ure, hats and shoes were removed, and the gentle pressing of hair has been made. The data were collected using a mobile data collection tool called Open Data Kit (ODK), and the collected data was directly sent to the KoBo Toolbox account created by the researchers. The daily data collected and submitted by the data enumerators were checked and cleaned by the researchers. Finally, the collected data were exported to STATA version 15 and made ready for data analysis. Standardization of measurements has been carried out, and the coefficient of variation was kept minimal $(<3 \%)$ for weight and height measurements.

\section{Data management and analysis}

The data were cleaned and prepared for analysis, and STATA version 15 (StataCrop LLC, College Station, TX 77845, USA) was used to present the summary results and inferential statistics. Exploratory data analyses were done to identify missing values, influential outliers, and normality of data for both outcome and explanatory variables. Anthropometric data were exported to WHO Anthro Software version 3.2.2 to generate anthropometric indices for weight-for-length/height $Z$-score (WHZ), height/length-for-age $Z$-score (HAZ), weight-for-age $Z$ score (WAZ), and BMI-for-age Z-score (BAZ). Child nutritional status was determined using the above indices where each of the indices $<-2 \mathrm{SD}$ is categorized as wasted, stunted, underweight, and thin. The child overnutrition was also defined when BAZ score between +2 and $+3 \mathrm{SD}$ and greater than $+3 \mathrm{SD}$ reflecting the presence of overweight and obesity, respectively. We omitted outliers for WHZ and BAZ when less than -5 and greater than +5 and for HAZ and WAZ when the score less than -6 and greater than +6 , respectively [22]. We fitted a generalized linear model (GLM) to declare the presence of significant associations between anthropometric indices (WHZ, HAZ, WAZ, and BAZ) and different explanatory variables. Maximum likelihood estimation was used to estimate the parameters. We checked the assumption for GLM for independently distributed outcome variables; not more than $20 \%$ of the expected cells had less than 5 for goodness-of-fit measures and the presence of the relationship between the transformed response in terms of the link function and the explanatory variables. To assess confounding, factors were included in the model based on biological plausibility and known epidemiological predisposing factors such as socio-demographic characteristics, socio-economic status, food insecurity, and child feeding practices. 
Table 1 Distribution of socio-demographic characteristics of study participants in Dessie and Combolcha towns, northcentral Ethiopia May 2018

\begin{tabular}{|c|c|c|}
\hline \multicolumn{2}{|l|}{ Variables } & \multirow{2}{*}{$\begin{array}{l}\text { Frequency (\%) } \\
355(70.2)\end{array}$} \\
\hline Sex of household head & Male & \\
\hline & Female & $151(29.8)$ \\
\hline \multirow{5}{*}{$\begin{array}{l}\text { Age of household head (in } \\
\text { years) }\end{array}$} & $<25$ & $63(12.5)$ \\
\hline & $25-30$ & $205(40.5)$ \\
\hline & $31-35$ & $108(21.3)$ \\
\hline & $36-40$ & $63(12.5)$ \\
\hline & $>40$ & $67(13.2)$ \\
\hline \multirow[t]{2}{*}{ City } & Dessie & $358(70.8)$ \\
\hline & Combolcha & $148(29.2)$ \\
\hline \multirow[t]{5}{*}{ Village } & Aba Kolba & $9(1.8)$ \\
\hline & Erfo & $139(27.5)$ \\
\hline & Arada & $77(15.2)$ \\
\hline & Hotie & $248(49)$ \\
\hline & Buanbua Wuha & $33(6.5)$ \\
\hline \multirow[t]{3}{*}{ Maternal educational status } & Formal & $440(89)$ \\
\hline & Informal & $28(5.5)$ \\
\hline & Non-educated & $38(7.5)$ \\
\hline \multicolumn{2}{|c|}{ Total average expenditure (in ETB) } & $4916 \pm 2766.9$ \\
\hline \multicolumn{2}{|c|}{ Estimated average household monthly income (in ETB) } & $\begin{array}{l}5644.9 \pm \\
3933.3\end{array}$ \\
\hline \multirow[t]{3}{*}{ Socio-economic status } & Poor & $173(34.3)$ \\
\hline & Medium & $190(37.7)$ \\
\hline & Rich & $141(28.0)$ \\
\hline \multirow[t]{4}{*}{ Source of income } & Employment only & $170(33.6)$ \\
\hline & Casual labor only & 79 (15.6) \\
\hline & $\begin{array}{l}\text { Non-agricultural } \\
\text { only }\end{array}$ & $83(16.4)$ \\
\hline & Multiple sources & $174(34.4)$ \\
\hline \multirow[t]{2}{*}{ Access for latrine } & Yes & $288(56.9)$ \\
\hline & No & $218(43.1)$ \\
\hline
\end{tabular}

\section{Ethical consideration}

During data collection, a letter of ethical clearance was collected from the Wollo University, College of Medicine and Health Sciences. Particularly, the institutional health research ethics review committee was consulted about the importance of the research to the community and the harms that would occur during data collection. An official letter has been written for each city administrator and health office where the data were taken. In addition, informed verbal consent was obtained from each client, and confidentiality was maintained by giving codes for each respondent rather than recording their names. Data collectors were informed that clients have full right to discontinue or refuse to participate in the study.

\section{Results}

Socio-demographic features of participants

A total of 506 mothers with child pairs were provided a complete response that gives a response rate of $98.8 \%$. The mean age of the household head was found to be $32.2( \pm 8.5 \mathrm{SD})$ years, and $355(70.2 \%)$ of the study subjects were male household headed. Regarding the marital status of the participants, majority (459 (90.7\%)) of them were married (Table 2). The average family sizes per household were $4.7( \pm 1.9 \mathrm{SD})$ (Table 1).

\section{Household food security and socio-economic characteristics of participants}

About the sources of drinking water, majority (445 $(87.9 \%))$ of the respondents had a private pipeline in their compounds while the rest used from communal pipe and spring water sources. On the other side, about two fifth $(43.1 \%)$ of the study participants used a latrine outside their home that might be from communal latrine or open defecation (Table 1).

The study reported that from the total of study subjects, 168 (33.1\%) of them were found in households that experienced any form of food insecurity. The extent of food insecurity was much worse among households who are female-headed than male-headed $(57.3 \%$ vs $22.9 \%, p$ $<0.0001$ ) (Fig. 1), and it was more than twofolds higher in households of non-educated mothers $(76.3 \%)$ compared to educated mothers $(28.5 \%)(p<0.0001)$.

\section{Child feeding practices}

Among all children, 449 (88.7\%) of them had good dietary diversity who consumed four and above food groups. Of the $24 \mathrm{~h}$ recall, the most common or staple food group consumed by children was pulses and nuts followed by cereals. However, consumption of iron-, zinc-, and vitamin A-rich animal source foods was eaten by less than $50 \%$ of the children (Fig. 2).

When compared to child's diversified eating habits across the household socio-economic classes, good dietary diversity was higher among children from poor classes compared to rich socio-economic category (62\% vs $22 \%, p<0.0001$ ), while it was higher among children from food-secure households compared to an insecure one $(69.4 \%$ vs $24 \%, p<0.0001)$. Additionally, children from educated mothers, married women, and maleheaded households had at least twofolds of better dietary diversity as compared to those from non-educated mothers, unmarried women, and female-headed households, respectively (Table 2).

\section{Child nutritional status}

From a total of 316 children who had complete data for weight-for-height $Z$-score, 17 (5.4\%) of them were wasted and boys seemed to be more affected than girls 


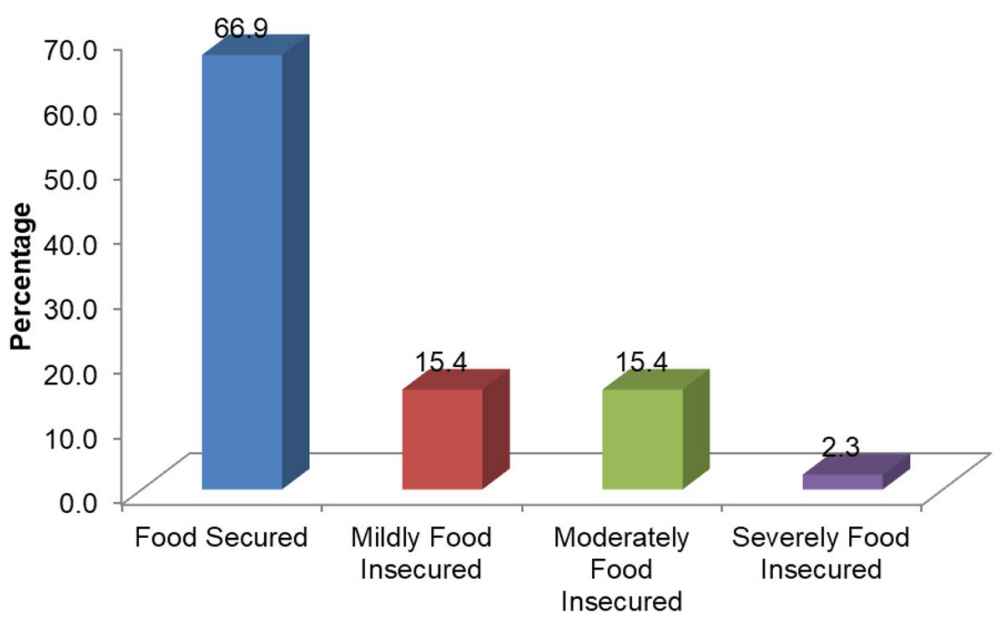

Fig. 1 Food security condition among households living in Dessie and Combolcha towns, north-central Ethiopia May 2018

(5.8\% vs 4.3\%). Similar results were found between WHZ and BAZ to illustrate the burden of acute malnutrition among children. By BAZ scores (<-2 SD), 5.2\% (95\% CI 3.2, 8.4) of children were acutely malnourished. Regarding the degree of chronic undernutrition from 340 children, about two of every five children were stunted (42.9\%; 95\% CI 37.4, 48.6), and of which $21.4 \%$ (95\% CI 17.4, 26.2) and 25.2\% (95\% CI 20.9, 30.2) were moderately and severely stunted, respectively. On the other hand, the proportion of children who had either wasting or stunting or both was $10.5 \%$ (95\% CI 7.5, 14.5). The co-existence of a double burden of malnutrition in the area was observed. Of all children, $42.2 \%$ (95\% CI 36.8, 47.9) of them were overweight and/or obese. With the BAZ score of greater than 3, and between 2 and 3 of SD, 27.9\% (95\% CI 23.2, 33.1) and $15.2 \%$ (95\% CI 11.7, 19.7) of children were categorized as having obesity and overweight, respectively.
The mean of WHZ, HAZ, BAZ, and WAZ scores (SD) was 1.35 ( \pm 2.03$),-1.89$ ( \pm 1.79$), 1.39$ ( \pm 2.06$)$, and 0.05 ( \pm 1.54), respectively. The presence of a linear relationship between different anthropometric indices and many covariates was examined (Table 3). Child age $(r=0.18, p$ $=0.02)$, child dietary diversity $(r=0.3, p<0.0001)$, and animal source food score $(r=0.23, p<0.0001)$ were positively correlated with child WHZ score, but the food insecurity score $(r=-0.11, p<0.04)$ was negatively correlated, while HAZ score was positively correlated with age of household head $(r=0.17, p<0.001)$ but negatively correlated with child dietary diversity scores $(r=$ $-0.18, p<0.001)$, child age $(r=-0.2, p<0.0001)$, and animal source food $(r=-0.15, p<0.006)$.

\section{Determinants of child nutritional status}

Potential candidate covariates were included in the generalized linear model to identify their level of statistical

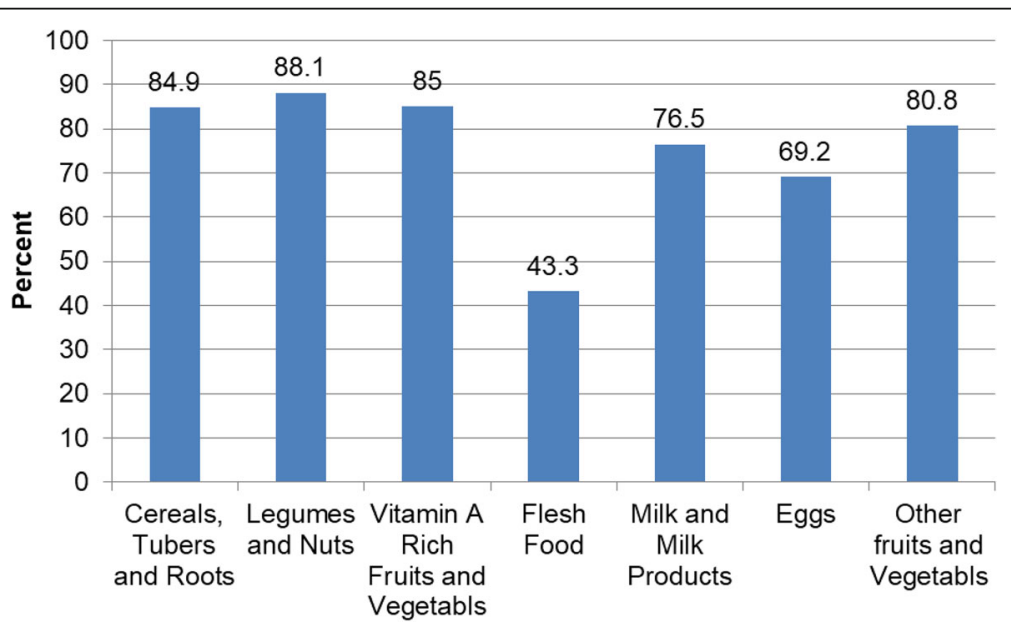

Fig. 2 Distribution of food groups consumed by children during $24 \mathrm{~h}$ prior to the data collection period in north-central Ethiopia 
Table 2 Associations of child dietary diversity scores and food insecurity condition with socio-demographic features of the respondents in north-central Ethiopia May 2018

\begin{tabular}{|c|c|c|c|c|c|c|c|c|}
\hline \multirow[t]{2}{*}{ Variables } & & \multicolumn{4}{|c|}{ Child dietary diversity score (CDDS) } & \multicolumn{3}{|c|}{ Food security status } \\
\hline & & Poor $(0-3)$ & Medium (4-5) & Good (6-7) & $p$ value & Food secure & Food insecure & $p$ value \\
\hline \multirow[t]{2}{*}{ Sex of household head } & Male & $23(6.48)$ & $112(31.54)$ & $220(61.97)$ & 0.0001 & $273(77.12)$ & $81(22.9)$ & 0.0001 \\
\hline & Female & $33(22)$ & $62(41.33)$ & $55(36.67)$ & & $64(42.67)$ & $86(57.33)$ & \\
\hline \multirow[t]{2}{*}{ Food security situation } & Food secure & $10(3 \%)$ & $93(27.6 \%)$ & $234(69.4 \%)$ & 0.0001 & & & \\
\hline & Food insecure & $46(27.5 \%)$ & $81(48.5 \%)$ & 40 (24\%) & & & & \\
\hline \multirow[t]{2}{*}{ Sex of child } & Male & $20(8.9 \%)$ & $69(30.8 \%)$ & $136(61.3 \%)$ & 0.253 & $164(74.2 \%)$ & $58(25.8 \%)$ & 0.002 \\
\hline & Female & $36(12.9 \%)$ & $105(37.6 \%)$ & $139(50.5 \%)$ & & $170(60.9 \%)$ & 109 (39.1\%) & \\
\hline \multirow[t]{3}{*}{ Mothers' education } & Formal & $37(7.5 \%)$ & $150(34.2 \%)$ & 256 (58.3\%) & 0.0001 & 255 (78\%) & $72(22 \%)$ & 0.0001 \\
\hline & Informal & $4(14.3 \%)$ & 15 (53.6\%) & $9(32.1 \%)$ & & $9(60 \%)$ & $6(40 \%)$ & \\
\hline & Non-educated & $19(50 \%)$ & $9(23.7 \%)$ & $10(26.3 \%)$ & & $9(75 \%)$ & $3(25 \%)$ & \\
\hline \multirow[t]{4}{*}{ Marital status } & Divorced & $9(31 \%)$ & 10 (34.5\%) & 10 (34.5\%) & 0.0001 & $2(20 \%)$ & $8(80 \%)$ & 0.0001 \\
\hline & Married & $40(8.7 \%)$ & $158(34.4 \%)$ & 261 (56.9\%) & & 320 (69.9\%) & $138(30.1 \%)$ & \\
\hline & Unmarried & 2 (28.6\%) & $3(42.9 \%)$ & $2(28.6 \%)$ & & $5(71.4 \%)$ & $2(28.6 \%)$ & \\
\hline & Widowed & $5(50 \%)$ & $3(30 \%)$ & $2(20 \%)$ & & $10(34.5 \%)$ & 19 (65.5\%) & \\
\hline \multirow[t]{3}{*}{ Wealth index } & Poor & $9(5.2 \%)$ & 57 (33.1\%) & $106(61.6 \%)$ & 0.0001 & 73 (36.3\%) & $128(63.6 \%)$ & 0.0001 \\
\hline & Medium & $3(1.6 \%)$ & $51(26.8 \%)$ & $136(71.6 \%)$ & & 85 (79.4\%) & 22 (20.6\%) & \\
\hline & Rich & $44(31.2 \%)$ & 66 (46.8\%) & 31 (22\%) & & 177 (91.2\%) & 17 (8.8\%) & \\
\hline
\end{tabular}

significance with different child anthropometric indices. Anthropometric indices WHZ, HAZ, WAZ, and BAZ scores as dependent variables were tested with the area of child residence, sex of household head, family size, age of mother, education of mother, marital status, age and sex of child, wealth index score, food insecurity, child dietary diversity score, and animal source food score. After adjustment of the model, child WHZ had significant positive or negative associations with the place of residence $[\beta=-1.33 ; 95 \% \mathrm{CI}-1.78,-0.89]$, sex of household head $[\beta=-0.97 ; 95 \% \mathrm{CI}-1.56,-0.35]$, child age $[\beta=0.31 ; 95 \%$ CI $0.13,0.50]$, and child DDS $[\beta$ $=0.48 ; 95 \%$ CI $0.28,0.69]$. When a unit increase in child dietary diversity score, the child WHZ score increased

Table 3 Correlation of child anthropometric indices with selected socio-economic and demographic variables and child feeding practices in north-central Ethiopia May 2018

\begin{tabular}{|c|c|c|c|c|c|c|}
\hline Variables & & WHZ & HAZ & BAZ & WAZ & MUACZ \\
\hline \multirow[t]{2}{*}{ Age of $\mathrm{HHH}$ (years) } & Correlation coefficient & -0.06 & 0.17 & -0.065 & 0.144 & 0.095 \\
\hline & $p$ value & 0.29 & 0.001 & 0.25 & 0.002 & 0.04 \\
\hline \multirow[t]{2}{*}{ Family size } & Correlation coefficient & 0.03 & 0.03 & 0.02 & 0.10 & 0.06 \\
\hline & $p$ value & 0.59 & 0.60 & 0.73 & 0.02 & 0.20 \\
\hline \multirow[t]{2}{*}{ Age of child (in months) } & Correlation coefficient & 0.18 & -0.20 & 0.14 & -0.19 & 0.10 \\
\hline & $p$ value & 0.002 & 0.0001 & 0.011 & 0.0001 & 0.025 \\
\hline \multirow[t]{2}{*}{ Wealth index score } & Correlation coefficient & -0.07 & 0.03 & -0.07 & -0.09 & -0.08 \\
\hline & $p$ value & 0.19 & 0.53 & 0.20 & 0.04 & 0.09 \\
\hline \multirow[t]{2}{*}{ Food insecurity score } & Correlation coefficient & -0.11 & 0.11 & -0.13 & -0.10 & -0.05 \\
\hline & $p$ value & 0.04 & 0.050 & 0.025 & 0.03 & 0.25 \\
\hline \multirow[t]{2}{*}{ Child dietary diversity score } & Correlation coefficient & 0.30 & -0.18 & 0.31 & 0.20 & 0.11 \\
\hline & $p$ value & 0.0001 & 0.001 & 0.0001 & 0.0001 & 0.014 \\
\hline \multirow[t]{3}{*}{ Animal source food score } & Correlation coefficient & 0.23 & -0.15 & 0.24 & 0.16 & 0.17 \\
\hline & $p$ value & 0.0001 & 0.006 & 0.0001 & 0.0001 & 0.0001 \\
\hline & $N$ & 317 & 340 & 315 & 474 & 480 \\
\hline
\end{tabular}


by about 0.5 . Similarly, WAZ has shown significant positive associations with child dietary diversity score and age of mother at $[\beta=0.26,95 \%$ CI $0.12,0.39]$ and $[\beta=$ $0.01 ; 95 \%$ CI $0.001,0.03$ ] successively and negative significant associations with child place residence $[\beta=-$ $0.24 ; 95 \%$ CI $-0.34,-0.13]$ and child age $[\beta=-1.03$; $95 \%$ CI $-1.33,-0.73]$.

In addition, HAZ score showed a significant positive association with age of mother $[\beta=0.03$; $95 \%$ CI 0.01 ; 0.05], education of mother [ $\beta=0.66 ; 95 \%$ CI $0.03,1.29]$, sex of child $[\beta=0.50 ; 95 \%$ CI $0.13,0.87]$, and animal source food score $[\beta=0.30 ; 95 \%$ CI $0.01,0.58]$. But it was negatively correlated with wealth index, child age, and child dietary diversity score at $\beta=-0.02,95 \% \mathrm{CI}-$ $0.07,0.03 ; \beta=-0.25,95 \% \mathrm{CI}-0.45,-0.06$; and $\beta=-$ $0.36,95 \%$ CI $-0.53,-0.20$, respectively (Table 4 ). For instance, the study indicated that as the child dietary diversity score increased by one unit, child linear growth decreased by about 0.5 and showed moderate strength of association.

Child anthropometric index by BAZ score was negatively affected by child place of residence $[\beta=-1.23$; $95 \% \mathrm{CI}-1.7,-0.78]$ and sex of household head $[\beta=-$ 0.07 ; $95 \% \mathrm{CI}-1.36,-0.08]$, but it was also positively affected by child's age $[\beta=0.23 ; 95 \% \mathrm{CI} 0.04,0.42]$ and child DDS $[\beta=0.48 ; 95 \%$ CI $0.26,0.69]$. In terms of residence, a child who lived in Dessie showed a decreased BAZ score of 1.2 points as compared to a child who lived in Combolcha. However, as a child's dietary diversity score increased by one unit, the child's BAZ score also increased by 0.5 scores (Table 4 ).

\section{Discussion}

The study revealed the double burden of malnutrition in the context of the urban food system remained a major public health challenge. The degree of chronic undernutrition and overnutrition posed severe major public concern, in which about $43 \%$ and $42 \%$ of children in Dessie and Combolcha towns, respectively, were stunted and overweight and/or obese. Given that the mean $( \pm$ SD) HAZ and BAZ scores were $-1.89( \pm 1.79)$ and $1.39( \pm$ $2.06)$, respectively, a significant number of children were categorized as stunted and overweight/obese. In the urban settings, the rate of malnutrition among underfive children was persistently higher, and the nutrition transition phenomenon impacted the health of children in which the rate of obesity has been radically progressed and that ultimately attributed to many lifethreatening non-communicable diseases including dietrelated cardio-metabolic risk and cancer [6, 23, 24]. The prevalence of chronic undernutrition in these urban settings was much higher than from studies conducted in urban settings of Ethiopia in Arba Minch (18.7\%) [25], Addis Ababa (19.6\%) [17], Kersa district (8.9\%) [26], rural Kenya (32\%) [27], South Africa (35\%) [28], and urban cities of South Africa, Umlazi (28\%), Rietvlei (20\%), and Paarl (17\%) [4]. However, it was less than the findings in rural and pre-urban areas in Ethiopia such as Humbo districts (75\%) [29], Merhabete district (52.4\%) [30], Libo-kemekem district (49.4\%) [31], and Lalibela town $(47.3 \%)$ [32]. On the other side, the finding was in line with the national prevalence of stunting from EDHS 2016 (38.39\%) [33], (37\%) [34] reports, Mecha (37.9\%)

Table 4 Generalized linear model identifying factors influencing child nutrition status in north-central Ethiopia May 2018

\begin{tabular}{|c|c|c|c|c|}
\hline \multirow[t]{2}{*}{ Explanatory variables } & \multicolumn{4}{|l|}{ Child malnutrition } \\
\hline & $\mathrm{WHZ}, \beta(95 \% \mathrm{Cl})$ & $\mathrm{HAZ}, \beta(95 \% \mathrm{Cl})$ & WAZ, $\beta(95 \% \mathrm{Cl})$ & $\mathrm{BAZ}, \beta(95 \% \mathrm{Cl})$ \\
\hline City (0 = Combolcha, 1 = Dessie) & $\begin{array}{l}-1.33(-1.78,- \\
0.89)^{* * *}\end{array}$ & $0.21(-0.19,0.61)$ & $\begin{array}{l}-1.03(-1.33,- \\
0.73)^{* * *}\end{array}$ & $\begin{array}{l}-1.23(-1.7,- \\
0.78)^{* * *}\end{array}$ \\
\hline $\begin{array}{l}\text { Sex of household head }(0=\text { female, } 1= \\
\text { male) }\end{array}$ & $\begin{array}{l}-0.97(-1.56,- \\
0.35)^{* * *}\end{array}$ & $0.30(-0.25,0.87)$ & $0.18(-0.50,0.14)$ & $\begin{array}{l}-0.07(-1.36,- \\
0.08)^{*}\end{array}$ \\
\hline Family size & $-0.004(-0.17,0.16)$ & $0.02(-0.06,0.12)$ & $0.04(-0.03,0.11)$ & $-0.02(-0.19,0.15)$ \\
\hline Age of mother & $-0.01(-0.04,0.02)$ & $0.03(0.009,0.05)^{* *}$ & $0.01(0.001,0.03)^{*}$ & $-0.01(-0.05,0.01)$ \\
\hline $\begin{array}{l}\text { Education of mother ( } 1=\text { formal, otherwise } \\
=0)\end{array}$ & $-0.19(-0.89,0.51)$ & $0.66(0.03,1.29)^{*}$ & $0.18(-0.24,0.60)$ & $-0.54(-1.25,0.17)$ \\
\hline Marital status $(1=$ married, otherwise $=0)$ & $0.23(-0.5,1.03)$ & $0.08(-0.65,0.82)$ & $0.21(-0.29,0.70)$ & $0.33(-0.49,1.14)$ \\
\hline Wealth index & $0.02(-0.04,0.07)$ & $-0.02(-0.07,0.03)$ & $-0.004(-0.03,0.03)$ & $0.02(-0.03,0.08)$ \\
\hline Food insecurity ( 0 = secure, $1=$ insecure) & $0.08(-0.43,0.61)$ & $-0.09(-0.56,0.37)$ & $0.02(-0.31,0.35)$ & $0.21(-0.32,0.75)$ \\
\hline Child age & $0.31(0.13,0.50)^{* *}$ & $\begin{array}{l}-0.36(-0.53,- \\
0.20)^{* * *}\end{array}$ & $\begin{array}{l}-0.24(-0.34,- \\
0.13)^{* * *}\end{array}$ & $0.23(0.04,0.42)^{*}$ \\
\hline Sex of child ( 1 = male, 0 = female) & $-0.13(-0.55,0.28)$ & $0.50(0.13,0.87)^{* *}$ & $0.15(-0.11,0.41)$ & $-0.25(-0.68,0.17)$ \\
\hline Child dietary diversity score & $0.48(0.28,0.69)^{* * *}$ & $\begin{array}{l}-0.25(-0.45,- \\
0.06)^{* *}\end{array}$ & $0.26(0.12,0.39)^{* * *}$ & $0.48(0.26,0.69)^{* * *}$ \\
\hline Animal source food & $-0.21(-0.52,0.09)$ & $0.30(0.01,0.58)^{*}$ & $0.04(-0.15,0.24)$ & $-0.22(-0.54,0.09)$ \\
\hline
\end{tabular}

Significance at $p$ value of ${ }^{*}<0.05,{ }^{* *} 0.01$, and ${ }^{* * * *} 0.001$ 
[35] and Arba Minch Health and Demographic Surveillance Site (41.9\%) [36], urban poor settings of Kenya (46\%) [27], and Dar-es-Salaam, Tanzania (43\%) [37]. In addition to the high burden of stunting in the study settings, the rate of overweight/obesity among under-five children became a crosscutting issue, in which about two of every five children were affected by overweight/ obesity as illustrated by the current study. The finding was much higher than reports from Bahir Dar (6.9\%) [38]; Dire Dawa (14.7\%) [39]; Beijing, China (18.7\%) [40]; the urban poor setting of Nairobi, Kenya (9\%) [27]; and urban, rural, and mountain areas of Italy $(21.06 \%)$ [41]. The discrepancies might be due to the prolonged time difference between the current and the previous studies, the rapid growth of urbanization, population density and impact of nutrition transition, a shift to higher energy, ultra-processed food sugar, and saturated fat intake.

In the generalized linear model, after adjustments, child's various anthropometric indices in the study area had been influenced by socio-demographic features, socio-economic status, and child feeding practices. But it was not affected by the urban food insecurity status of the household. Child linear growth (literally called stature or HAZ score) were significantly associated with mothers' or caregivers' age and education, sex and age of the child, child DDS, and ASF, while the child's mean BAZ score was affected by the sex of household head, age of the child, and child DDS. Furthermore, children with a higher score of animal source food were less likely to have shorter statures.

Child diet diversity was inversely and significantly associated with child HAZ score, and it was contradicted with the findings in rural areas of Kenya and East and West Gojjam Zones of Amhara region, Ethiopia, implying that DDS was a proxy measure of childhood stunting [42, 43]. However, in another study conducted in Ethiopia, DDS had no indicated the presence of association with HAZ scores $[17,36]$. This could be the fact that the higher the diversity score may not be a guarantee for a higher mean HAZ score unless the food groups consumed may not include essential nutrients and the small sample size may affect the direction of the association in the current study. Unless the consumption in the study setting is not usual, $24 \mathrm{~h}$ recall might not reflect the actual relation between dietary diversity and chronic undernutrition. However, evidences showed that usual optimal feeding practices ultimately affect child growth and nutritional status positively [44]. As maternal age increases and mothers became more educated, the mean HAZ score also increased, that is, the child is less likely to become stunted. The finding was also congruent to the reports from EDHS 2016 [33], Northwest Ethiopia [35], Ecuador [45], South Africa [4, 46], five high-income countries (the USA, the UK, Australia, the
Netherlands, and Sweden) [47], Bangladesh [48], and China [49]. It is clear that as mothers get older, they experienced many lived skills and learned from their previous caring practices and educated mothers are also change-makers, innovators and capable enough to transfer knowledge and skills gained, and easily understand child feeding principles and the impact of malnutrition on their child's health $[17,23]$.

The child mean HAZ score was negatively affected as a child became aged which was compatible with shreds of evidence from China [49], Gojjam of Ethiopia [43], Southern Ethiopia [29], data from multilevel analysis of EDHS 2016 [33], northwest Ethiopia [30, 35], and Lalibela of Ethiopia [32], and being male in gender positively related with HAZ score similar with reports in Ethiopia [43] but in contrast to the studies from South Africa depicted that males are disproportionately affected by stunting [46], Western China [49]. These may be due to the fact that when the child gets older, they rely on the quality of complementary food, become independent and fed themselves, and get less attention given from parents.

The child BAZ score had shown a significant relation to child dietary diversity score and supported by studies conducted in Bahir Dar [38] and South Africa [46], but a study conducted in South Africa reflected the inverse association between DDS and BAZ [28] and Southern Ethiopia [36]. The possible justification for the higher mean of BAZ score among children with higher DDS is that the inclusion of a variety of foods from different groups did not contribute to optimum nutrition unless the balance or proportion of foods was taken into consideration. The energy contribution from energy-yielding nutrients should be within the recommended energy range and consumption of Western diet (processed, trans-fats, saturated fats) which leads to positive energy balance and leads to prompt adipose-tissue accumulation, must be restricted to combat the growing epidemic of obesity.

Children from male-headed households and reside in Dessie [50] were negatively related to child BAZ score, but child age had a positive relationship with BAZ score [50]. Even though there is no clear justification with the above relationships, in areas where maternal empowerment was less emphasized and decision-making power left only for males, maternal autonomies for child's feedings are affected. So, mothers or caregivers will face difficulty in providing food for their children for what they want and depend on the willingness of husbands. A child from Dessie was thinner than a child from Combolcha, and this may be due to Dessie is the third city by population-density in Ethiopia and recently covered by an urban-food security program following Addis Ababa. 
Many of the households faced chronic food insecurity, and the quality of dietary diversity was highly compromised in the area. In this study, when a child's age increases, the probability of being obese is higher. This may be related to frequent exposure of children to sweetened foods, soft drinks, and preference for processed foods which all are highly accessible in the area.

Food insecurity and socio-economic status of households in the urban context of the current study did not show association with any of the child anthropometric indicators which were similar to the reports from rural Cambodia [51], rural community of Southeastern Kenya [52], and urban poor children of Kenya [53]. A scoping review suggested that household food insecurity may not be associated with height inequalities among children in Canada and the USA and provided insufficient evidence to determine whether food insecurity is or is not associated with children's height in these countries [54]. Nevertheless, some other studies from the Tamale Metropolis of Northern Ghana, poor rural areas of China [55], and León, Nicaragua [56] agreed that children from food-insecure households were found in a higher probability of being stunted or had lower mean HAZ scores. But a study from Ecuador implicated that food insecurity affects child stature, but does not increase calorie intakes that lead to obesity [57].

This study has several limitations. It does not consider potential mediator variables such seasonal variability that may affect food insecurity and feeding practices, environmental factors, host factors, physical activity, and other lifestyle factors that cumulatively impact child stature and fat body composition of children. We cannot also discount the effect of nutrient intakes and details of food frequency for processed foods and fruits and vegetables. We excluded some data due to missing anthropometric measurements that may have introduced a selection bias (if not missing at random), and may thus have affected both the internal validity and the representativeness of the findings in the broader Ethiopian context.

\section{Conclusion and recommendation}

The study concludes that the co-existence of the double burden of malnutrition epidemics in urban settings. The presence of different forms of malnutrition is characteristics, rapid urbanization, population growth, and high inequalities. Both forms of malnutrition are calling for immediate interventions due to their severe public health concerns. Mothers' age and education, child's age, sex, and dietary diversity were the potential determinants of child's linear growth while the area of residence, sex of household head, child's age, and dietary diversity were the predisposing correlates of a child's body fat composition. The dual epidemic of undernutrition and overweight/obesity requires differential policy inputs in metropolitan areas. Very little obesity prevention interventions targeting children have been effective and a comprehensive, multifaceted strategy tackling diet, physical inactivity, coupled with psychosocial support and local food environment change may prove more effective. Nutrition policies tackling child obesity must promote household nutrition security and healthy growth, decrease overconsumption of nutrient-poor foods, better shield children from the increasingly pervasive marketing of energy-dense, nutrient-poor foods and sugarsweetened beverages as well as reduction of growing physical inactivity [47]. The cost of undernutrition in Ethiopia remained high, and it will be very complicated if childhood obesity is also added as a health challenge. Effective public health planning and contextually tailored interventions are required at the subnational level to address this challenge. Multi-sectoral action may work best given the complex nature of the prevailing circumstances in urban poor settings. Further research is needed to understand the pathways to this coexistence and to test the feasibility and effectiveness of contextspecific interventions to curb associated health risks.

\section{Abbreviations \\ ASF: Animal source food; BAZ: BMI-for-age Z-score; CL: Confidence level; DDS: Dietary diversity score; EDHS: Ethiopian Demographic and Health Survey; FAO: Food and Agriculture Organization; GLM: Generalized linear model; HAZ: Height-for-age Z-score; HFIAS: Household Food Insecurity Access Scale; IYCF: Infant and Young Child Feeding; MUACZ: Mid-upper arm circumference for age Z-score; PCA: Principal component analysis; \\ SD: Standard deviation; SES: Socio-economic status; WAZ: Weight-for-age Z- score; WHO: World Health Organization; WHZ: Weight-for-height Z-score}

\section{Acknowledgements}

We would like to thank Wollo University, Dessie; Combolcha Town Health Office data collectors; study participants; and supervisors for their substantial contribution for the accomplishment of the research.

\section{Authors' contributions}

AMD contributed to the conception, design, data collection, analysis, interpretation of the data, and drafting of the manuscript; gave final approval of the version to be published; and agreed to be accountable for all aspects of the work. TCM contributed to the conception, design, data collection, analysis, interpretation of the data, and drafting of the manuscript and gave final approval of the version to be published and agreed to be accountable for all aspects of the work. GSA contributed to the design, data collection, analysis, interpretation of the data, and revision of the manuscript; give final approval of the version to be published; and agreed to be accountable for all aspects of the work. These authors contributed equally to this work

\section{Funding}

Wollo University sponsored the financial support for the research work but has no role in the design, data collection, curation, and analysis of the study.

Availability of data and materials

The manuscript contains the all the data needed, and we can provide the dataset upon any request.

\section{Ethics approval and consent to participate}

Ethical clearance letters were collected from Wollo University research and community service directorate and Dessie and Combolcha town administrative offices to care for both the study participants and the researchers. The official letter was written for each sub-city where the data 
collection was targeted, and informed verbal consent has been obtained from each client and confidentiality has been maintained by giving codes for respondents rather than recording their names. Study participants were informed that they had full right to discontinue or refuse to participate in providing data. Therefore, all participants of the research including survey households, case studies, enumerators, the supervisors, and key informants were fully informed about the objectives of the study. They were approached in friendly and free moods.

\section{Competing interests}

The authors declared that they have no conflict of interest.

\section{Author details}

${ }^{1}$ Researcher at the Department of Rural Development and Agricultural Extension, College of Agriculture, Wollo University, Dessie, Ethiopia. ${ }^{2}$ Researcher at the School of Public Health, College of Medicine and Health Sciences, Wollo University, Dessie, Ethiopia. ${ }^{3}$ Researchr at the Department of Plant Science, College of Agriculture, Wollo University, Dessie, Ethiopia.

Received: 7 September 2020 Accepted: 16 November 2020 Published online: 02 December 2020

\section{References}

1. NCD Risk Factor Collaboration (NCD-RisC). Worldwide trends in body-mass index, underweight, overweight, and obesity from 1975 to 2016: a pooled analysis of 2416 population-based measurement studies in 128.9 million children, adolescents, and adults. Lancet. 2017;390(10113):2627-42. https://doi.org/10.1016/S0140-6736(17)32129-3.

2. Mbogori T, Kimmel K, Zhang M, Kandiah J, Wang Y. Nutrition transition and double burden of malnutrition in Africa: A case study of four selected countries with different social economic development. AIMS Public Health. 2020;7(3):425-39. https://doi.org/10.3934/publichealth.2020035.

3. Kimani-Murage EW, Muthuri SK, Oti SO, Mutua MK, van de Vijver S, et al. Evidence of a Double Burden of Malnutrition in Urban Poor Settings in Nairobi, Kenya. PLOS ONE. 2015;10(6):e0129943. https://doi.org/10.1371/ journal.pone.0129943.

4. Zembe-Mkabile $W$, et al. The dynamic relationship between cash transfers and child health: can the child support grant in South Africa make a difference to child nutrition? Public Health Nutr. 2015;19(2):356-62.

5. UNICEF, Improving child nutrition: the achievable imperative for global progress. Nework 2013

6. Turok I, Mcgranahan G. Urbanization and economic growth: The arguments and evidence for Africa and Asia. Environ Urban. 2013;25:465-82.

7. WB, Urban population growth (annual\%)-Ethiopia 2019

8. Horiuchi Y, Kusama K, Kanha S, Yoshiike N; FIDR research team. Urban-Rural Differences in Nutritional Status and Dietary Intakes of School-Aged Children in Cambodia. Nutrients. 2018;11(1):14. https://doi.org/10.3390/ nu11010014.

9. Holdsworth M, Landais E. Urban food environments in Africa: implications for policy and research. Proc Nutr Soc. 2019;78(4):513-25.

10. Garenne M. Urbanisation and child health in resource poor settings with special reference to under-five mortality in Africa. Arch Dis Child. 2010;95(6): 464-8.

11. Jomaa L, Mcdonnell E, Probart C. School feeding programs in developing countries: Impacts on children's health and educational outcomes. Nutr Rev. 2011;69(2):83-98.

12. Olack B, Burke H, Cosmas L, Bamrah S, Dooling K, Feikin DR, Talley LE, Breiman RF. Nutritional status of under-five children living in an informal urban settlement in Nairobi, Kenya. J Health Popul Nutr. 2011;29(4):357-63. https://doi.org/10.3329/jhpn.v29i4.8451.

13. USAID, Ethiopia: nutrition profile. Report 2018.

14. FDRE, Seqota Declaration Implementation Plan 2016-2030 Summary Programme Approach Document. Report 2016.

15. Agidew A-mA, Singh KN. Determinants of food insecurity in the rural farm households in South Wollo Zone of Ethiopia: the case of the Teleyayen subwatershed. Agric Food Econ. 2018;6(1):10. https://doi.org/10.1186/s40100018-0106-4.

16. WFP. Food Security and Vulnerability in Selected Towns of Afar and Amhara Regions, Ethiopia: WFP-Ethiopia Vulnerability Assessment and Mapping (VAM). 2009 ;( September).
17. Berhane HY, Jirström M, Abdelmenan S, Berhane Y, Alsanius B, Trenholm J, et al. Social stratification, diet diversity and malnutrition among preschoolers: a survey of Addis Ababa, Ethiopia. Nutrients. 2020;12(3):712.

18. Gwatkin DR, Rutstein S, Johnson K, Suliman E, Wagstaff A, Amouzou A. Socio-economic differences in health, nutrition, and population within developing countries: an overview. Niger J Clin Pract. 2007;10(4):272-82 Epub 2008/02/26. PubMed PMID: 18293634

19. Coates J, Swindale A, Bilinsky P. Household Food Insecurity Access Scale (HFIAS) for measurement of household food access: indicator guide (v. 3). Washington, DC: Food and Nutrition Technical Assistance Project, Academy for Educational Development; 2007. Available online: http://www.fao.org/ fileadmin/userupload/eufao-fsi4dm/doc-training/hfias.pdf.

20. Kennedy G, Razes M, Ballard T, Dop MC, editors. Measurement of dietary diversity for monitoring the impact of food based approaches. 2010.

21. Organization $\mathbf{W H}$. Indicators for assessing infant and young child feeding practices: part 2: measurement. 2010.

22. de Onis M, Onyango AW, Van den Broeck J, Chumlea WC, Martorell R. Measurement and standardization protocols for anthropometry used in the construction of a new international growth reference. Food Nutr Bull. 2004; 25(1 Suppl):S27-36. https://doi.org/10.1177/15648265040251s104 Epub 2004/04/090. PubMed PMID: 15069917.

23. Delpeuch F, Traissac P, Martin-Prevel Y, Massamba J, Maire B. Economic crisis and malnutrition: socioeconomic determinants of anthropometric status of preschool children and their mothers in an African urban area. Public Health Nutr. 2000;3:39-47.

24. Yan XY, Li Q, Luo BX, You TH, Wang HJ. Trend in the nutritional status of children aged 2-7 years in Luoding city, China: a panel study from 2004 to 2013. PLoS One. 2018;13(10):e0205163. https://doi.org/10.1371/journal.pone. 0205163 Epub 2018/10/04. PubMed PMID: 30281659; PubMed Central PMCI D: PMCPMC6169943.

25. Agedew $E$, Chane T. Prevalence of stunting among children aged 6-23 months in Kemba Woreda, Southern Ethiopia: a community based crosssectional study. Advances in Public Health. 2015;2015.

26. Mesfin F, Berhane $Y$, Worku A. Prevalence and associated factors of stunting among primary school children in Eastern Ethiopia. Nutr Diet Suppl. 2015;7:61-8.

27. Kimani-Murage EW, Muthuri SK, Oti SO, Mutua MK, van de Vijver S, Kyobutungi $\mathrm{C}$. Evidence of a double burden of malnutrition in urban poor settings in Nairobi, Kenya. PLoS One. 2015;10(6):e0129943. https://doi.org/10. 1371/journal.pone.0129943.

28. Chakona G, Shackleton CM. Household food insecurity along an agroecological gradient influences children's nutritional status in South Africa. Front Nutr. 2018;4:72-. doi: https://doi.org/10.3389/fnut.2017.00072. PubMed PMID: 29404332

29. Bogale TY, Bala ET, Tadesse M, Asamoah BO. Prevalence and associated factors for stunting among 6-12 years old school age children from rural community of Humbo district, Southern Ethiopia. BMC Public Health. 2018; 18(1):653.

30. Geberselassie SB, Abebe SM, Melsew YA, Mutuku SM, Wassie MM. Prevalence of stunting and its associated factors among children 6-59 months of age in Libo-Kemekem district, northwest Ethiopia; a community based cross sectional study. PLoS One. 2018;13(5):e0195361 e.

31. Abeway S, Gebremichael B, Murugan R, Assefa M, Adinew YM. Stunting and its determinants among children aged 6-59 months in northern Ethiopia: a cross-sectional study. J Nutr Metab. 2018;25:2018.

32. Yalew BM, Amsalu F, Bikes D. Prevalence and factors associated with stunting, underweight and wasting: a community based-cross sectional study among children age 6-59 months at Lalibela town, northern Ethiopia. J Nutr Disorders Ther. 2014:4:147. https://doi.org/10.4172/2161-0509.1000147.

33. Fantay Gebru K, Mekonnen Haileselassie W, Haftom Temesgen A, Oumer Seid A, Afework MB. Determinants of stunting among under-five children in Ethiopia: a multilevel mixed-effects analysis of 2016 Ethiopian demographic and health survey data. BMC Pediatr. 2019;19(1):176.

34. Ethiopian Public Health Institute (EPHI) [Ethiopia] and ICF. Ethiopia Mini Demographic and Health Survey 2019: Key Indicators. Rockville: EPHI and ICF; 2019

35. Lisanu Mazengia A, Andargie BG. Predictors of stunting among school-age children in Northwestern Ethiopia. J Nutr Metab. 2018;20:2018.

36. Zerihun E, Alemu G, Aschalew Z, Tariku B. Prevalence and factors associated with stunting and thinness among school-age children in Arba Minch Health and Demographic Surveillance Site, Southern Ethiopia. PLoS One. $2018 ; 13$. 
37. Kulwa KB, Kinabo $L$, Modest B. Constraints on good child-care practices and nutritional status in urban Dar-es-Salaam, Tanzania. Food Nutr Bull. 2006;27(3):236-44.

38. Tadesse Y, Derso T, Alene KA, Wassie MM. Prevalence and factors associated with overweight and obesity among private kindergarten school children in Bahirdar town, northwest Ethiopia: cross-sectional study. BMC Res Notes. 2017;10(1):22.

39. Desalew A, Mandesh A, Semahegn A. Childhood overweight, obesity and associated factors among primary school children in Dire Dawa, eastern Ethiopia; a cross-sectional study. BMC Obesity. 2017;4(1):20.

40. Shan X-Y, Xi BO, Cheng H, Hou D-Q, Wang Y, Mi JIE. Prevalence and behavioral risk factors of overweight and obesity among children aged 2 18 in Beijing, China. Int J Pediatr Obes. 2010;5(5):383-9.

41. Bertoncello C, Cazzaro R, Ferraresso A, Mazzer R, Moretti G. Prevalence of overweight and obesity among school-aged children in urban, rural and mountain areas of the Veneto region, Italy. Public Health Nutr. 2008;11(9): 887-90.

42. M'Kaibi FK, Steyn NP, Ochola SA, Du Plessis L. The relationship between agricultural biodiversity, dietary diversity, household food security, and stunting of children in rural Kenya. Food Sci Nutr. 2017;5(2):243-54.

43. Motbainor A, Worku A, Kumie A. Stunting is associated with food diversity while wasting with food insecurity among underfive children in East and West Gojjam zones of Amhara region, Ethiopia. PLoS One. 2015;10(8): e0133542.

44. Guo YF, Gan YY, Guo CN, Sun J, Hao LP. Nutritional status of under-five children from urban low-income families in Xiangtan and Jilin in China. J Huazhong Univ Sci Technol Med Sci. 2017;37(1):74-8.

45. Walrod J, Seccareccia E, Sarmiento I, Pimentel JP, Misra S, Morales J, et al. Community factors associated with stunting, overweight and food insecurity: a community-based mixed-method study in four Andean indigenous communities in Ecuador. BMJ Open. 2018;8(7):e020760.

46. Sartorius B, Sartorius K, Green R, Lutge E, Scheelbeek P, Tanser F, et al. Spatial-temporal trends and risk factors for undernutrition and obesity among children ( $<5$ years) in South Africa, 2008-2017: findings from a nationally representative longitudinal panel survey. BMJ Open. 2020;10(4): e034476.

47. Bird PK, Pickett KE, Graham H, Faresjö T, Jaddoe WW, Ludvigsson J, et al. Income inequality and social gradients in children's height: a comparison of cohort studies from five high-income countries. BMJ Paediatr Open. 2019; 3(1):e000568.

48. Ali NB, Tahsina T, Hoque DM, Hasan MM, lqbal A, Huda TM, El Arifeen S. Association of food security and other socio-economic factors with dietary diversity and nutritional statuses of children aged 6-59 months in rural Bangladesh. PLoS One. 2019;14(8):e0221929.

49. Wang A, Scherpbier RW, Huang X, Guo S, Yang Y, Josephs-Spaulding J, et al. The dietary diversity and stunting prevalence in minority children under 3 years old: a cross-sectional study in forty-two counties of Western China. $\mathrm{Br}$ J Nutr. 2017;118(10):840-8.

50. Weldearegay HG, Gebrehiwot TG, Abrha MW, Mulugeta A. Overweight and obesity among children under fve in Ethiopia: further analysis of 2016 national demographic health survey: a case control study. BMC Res Notes. 2019;12:716.

51. McDonald CM, McLean J, Kroeun H, Talukder A, Lynd LD, Green TJ. Household food insecurity and dietary diversity as correlates of maternal and child undernutrition in rural Cambodia. Eur J Clin Nutr. 2015;69(2):242-6.

52. Shinsugi C, Matsumura M, Karama M, Tanaka J, Changoma M, Kaneko S. Factors associated with stunting among children according to the level of food insecurity in the household: a cross-sectional study in a rural community of Southeastern Kenya. BMC Public Health. 2015;15:441.

53. Mutisya M, Kandala NB, Ngware MW, Kabiru CW. Household food (in)security and nutritional status of urban poor children aged 6 to 23 months in Kenya. BMC Public Health. 2015;15:1052.

54. Fafard St-Germain AA, Siddiqi A. The relation between household food insecurity and children's height in Canada and the United States: a scoping review. Adv Nutr (Bethesda, Md). 2019;10(6):1126-37.

55. Yang Q, Yuan T, Yang L, Zou J, Ji M, Zhang Y, et al. Household food insecurity, dietary diversity, stunting, and anaemia among left-behind children in poor rural areas of China. Int J Environ Res Public Health. 2019; 16(23):4778
56. Schmeer KK, Piperata BA. Household food insecurity and child health. Matern Child Nutr. 2017;13(2):e12301 https://doi.org/10.1111/mcn.12301. Epub 2016 Apr 29.

57. Weigel MM, Armijos RX, Racines M, Cevallos W. Food insecurity is associated with undernutrition but not overnutrition in Ecuadorian women from lowincome urban neighborhoods. J Environ Public Health. 2016;2016:8149459.

\section{Publisher's Note}

Springer Nature remains neutral with regard to jurisdictional claims in published maps and institutional affiliations.
Ready to submit your research? Choose BMC and benefit from:

- fast, convenient online submission

- thorough peer review by experienced researchers in your field

- rapid publication on acceptance

- support for research data, including large and complex data types

- gold Open Access which fosters wider collaboration and increased citations

- maximum visibility for your research: over $100 \mathrm{M}$ website views per year

At BMC, research is always in progress.

Learn more biomedcentral.com/submissions 